\title{
EDITORIAL / REDAKSIONEEL
}

This edition of the JJS sees the first publication of a public lecture under the journal's new rubric "Praelectiones tsa rona", which is a combination of Latin and Sesotho meaning "Eminent lectures of ours". I would like to thank my colleagues Mr Khanya Motshabi and Ms Lebo Moshe-Bereng for their inputs in coming up with a title that so aptly reflects - and celebrates - our unique and broadly South African legal and cultural heritage, and moreover does so in the Free State's regional context.

Of course, it goes without saying that a word of gratitude is also due to Mr Justice Dennis Davis for kindly agreeing to publish his lecture "Authoritarian constitutionalism: The South African experience" in the pages that follow.

Finally, I would also like to thank my co-managing editor, Dr Jacques Matthee, for his invaluable contribution towards the effective running of the journal during a particularly challenging year.

\section{Bradley Smith Managing Editor}

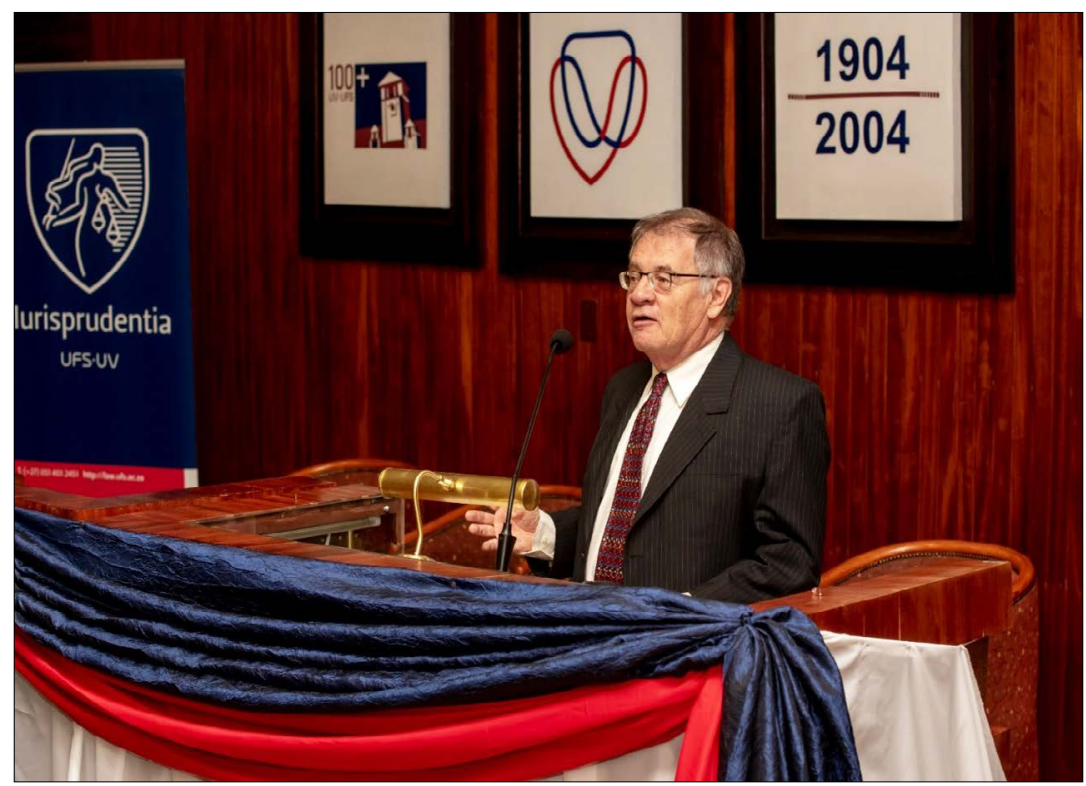

Judge Dennis Davis delivering his lecture at the UFS on 13 May 2019.

(Photograph by Sonia Small (Kaleidoscope Studios)) 